\title{
Response to'Pain persists in DAS28 rheumatoid arthritis remission but not in ACR/EULAR remission: a longitudinal observational study'
}

\author{
Kazuki Yoshida'*, Kazuo Matsui', Hiroto Nakano', Hideto Oshikawa', Masako Utsunomiya', Tatsuo Kobayashi', \\ Makiko Kimura', Gautam A Deshpande² and Mitsumasa Kishimoto ${ }^{3}$
}

See related research by Lee et al., http://arthritis-research.com/content/13/3/R83

We read with interest the report by Lee and colleagues in the June issue of Arthritis Research \& Therapy [1]. The study compared the Disease Activity Score in 28 joints calculated by using C-reactive protein (DAS28-CRP) versus American College of Rheumatology/European League Against Rheumatism (ACR/EULAR) remission in terms of residual pain. The authors stated that DAS28CRP remission criteria allowed for persistence of pain in more than $10 \%$ of patients, whereas there were very few complaints of pain among patients in ACR/EULAR remission. This is a very important finding as it clearly demonstrated incompetence of the DAS28-CRP remission criteria in defining remission that is meaningful for patients, thus encouraging transition to new ACR/ EULAR remission criteria.

One factor, however, that was not mentioned in the article and which may be of interest is the Disease Activity Score in 28 joints calculated by using erythrocyte sedimentation rate (DAS28-ESR). Although the DAS28CRP is a validated score demonstrating good correlation with the DAS28-ESR [2], the DAS28-CRP frequently results in lower scores than its erythrocyte sedimentation rate counterpart $[2,3]$. Inoue and colleagues thus suggested a different cut-off point of 2.3 for the DAS28-CRP [3]. This tendency was also demonstrated in our cohort of 265 rheumatoid arthritis patients taking biologics (Figure 1). When plotted against the DAS28-ESR, the DAS28-CRP resulted in lower values (below the diagonal line, indicating complete agreement) more often than not. Also noteworthy is that the DAS28-CRP is never lower than 0.96 , which is the constant term in the following equation [4]:

*Correspondence: kazukiyoshid@gmail.com

'Department of Rheumatology, Kameda Medical Center, 929 Higashi-Cho,

Kamogawa City, Chiba Prefecture 296-8602, Japan

Full list of author information is available at the end of the article

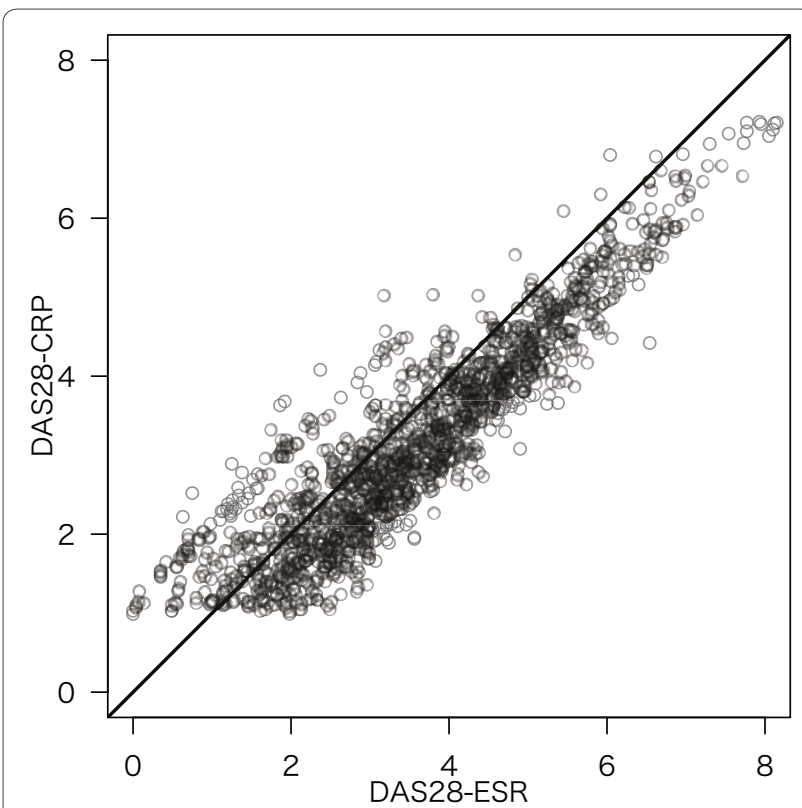

Figure 1. Relationship between the Disease Activity Scores in 28 joints calculated by using C-reactive protein and erythrocyte sedimentation rate. Relationship between the Disease Activity Score in 28 joints calculated by using C-reactive protein (DAS28(RP) and the Disease Activity Score in 28 joints calculated by using erythrocyte sedimentation rate (DAS28-ESR) in our biologic cohort.

$$
\begin{gathered}
\text { DAS28-CRP }=0.56 \times \sqrt{ } \mathrm{TJC} 28+0.28 \times \\
\sqrt{\mathrm{SJC} 28}+0.36 \times \ln (\mathrm{CRP}+1)+0.014 \times \mathrm{GH}+0.96
\end{gathered}
$$

in which TJC stands for tender joint count, SJC for swollen joint count, ln for natural logarithm, CRP for Creactive protein, and $\mathrm{GH}$ for global health as reported by the patient.

We therefore wonder whether Lee and colleagues performed the same analysis with DAS28-ESR remission criteria. We think it may be interesting to perform the same analysis with DAS28-ESR remission criteria or a stricter DAS28-CRP cut-off point of 2.3. 


\section{Abbreviations}

ACR/EULAR, American College of Rheumatology/European League Against Rheumatism; DAS28-CRP, Disease Activity Score in 28 joints calculated by using C-reactive protein; DAS28-ESR, Disease Activity Score in 28 joints calculated by using erythrocyte sedimentation rate.

\section{Competing interests}

The authors declare that they have no competing interests.

\section{Author details}

'Department of Rheumatology, Kameda Medical Center, 929 Higashi-Cho, Kamogawa City, Chiba Prefecture 296-8602, Japan. ${ }^{2}$ Center for Clinical Epidemiology, St. Luke's International Hospital, 9-1 Akashicho, Chuo-ku, Tokyo, 104-8560, Japan. ${ }^{3}$ Division of Allergy and Rheumatology, St. Luke's International Hospital, 9-1 Akashicho, Chuo-ku, Tokyo, 104-8560, Japan.

Published: 18 August 2011

\section{References}

1. Lee YC, Cui J, Lu B, Frits ML, lannaccone CK, Shadick NA, Weinblatt ME, Solomon DH: Pain persists in DAS28 rheumatoid arthritis remission but not in ACR/EULAR remission: a longitudinal observational study. Arthritis Res Ther 2011, 13:R83.

2. Wells G, Becker J-C, Teng J, Dougados M, Schiff M, Smolen J, Aletaha D, van Riel PLCM: Validation of the 28-joint Disease Activity Score (DAS28) and European League Against Rheumatism response criteria based on C-reactive protein against disease progression in patients with rheumatoid arthritis, and comparison with the DAS28 based on erythrocyte sedimentation rate. Ann Rheum Dis 2009, 68:954-960.

3. Inoue E, Yamanaka H, Hara M, Tomatsu T, Kamatani N: Comparison of Disease Activity Score (DAS)28-erythrocyte sedimentation rate and DAS28-C-reactive protein threshold values. Ann Rheum Dis 2007. 66:407-409.

4. DAS-SCORE.NL: Home of the DAS [http://www.das-score.n//]

doi:10.1186/ar3393

Cite this article as: Yoshida K, et al:: Response to 'Pain persists in DAS28 rheumatoid arthritis remission but not in ACR/EULAR remission: a longitudinal observational study'. Arthritis Research \& Therapy 2011, 13:405. 